\title{
IDENTIFICATION OF INDUCTION MACHINE PARAMETERS USING ONLY NO-LOAD TEST MEASUREMENTS
}

\author{
M. Aminu ${ }^{1,}{ }^{*}$, P. K. Ainah ${ }^{2}$, M. Abana ${ }^{3}$ and U. A. Abu ${ }^{4}$

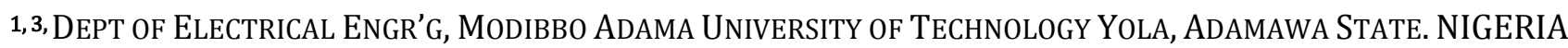

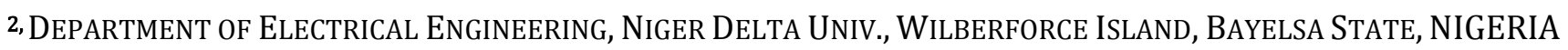 \\ 4, Department of Electrical EngineERING, Federal PolyteChnic IdA, KoGi State, NIGERIA \\ E-mail addresses: ${ }^{1}$ aminumhd@gmail.com, ${ }^{2}$ kennethainah@gmail.com, ${ }^{3}$ munzal21@gmail.com, \\ 4 abuattaiumar@yahoo.com
}

\begin{abstract}
Several methods have been used to estimate the parameters of induction machines. The basic method is the standard no-load and block rotor test. Although accurate results are obtained using this method; however, performing the locked rotor test is difficult, requiring full control of the voltage by using appropriate instrument to mechanically secure the rotor in the locked condition. Therefore, in this paper, a method requiring only a no-load test to extract the parameters of the induction machine is presented. The proposed method is based on the modification of the third impedance calculation of the IEEE standard 112. To validate the proposed method, parameters of a standard 7.5kW induction machine are estimated. Based on the experimental results, the maximum recorded error in the parameter estimation is less than $-2.881 \%$ when compared to the reference parameters obtained from the conventional no-load and blocked rotor test.
\end{abstract}

Keywords: induction motor, no-load tests, machine parameters, third impedance calculation, blocked-rotor test

\section{INTRODUCTION}

Induction machines are considered as the workhorse of industry due to their low cost, reliability, robustness and low maintenance cost. Several key applications involving the induction machine, require accurate parameter estimation to properly assess the machine's performance. Considerable interest has been given in developing new and improved methods for the induction machine parameter estimation. Several international efficiency estimation standards have been developed for induction machines. The most prominent amongst these standards are the IEEE standard 1122004 and the IEC standard 60034-2-1. The equivalent circuit approach is one of the method found in both standards that involves identifying the induction machine's equivalent circuit parameters for efficiency estimation.

In the IEEE standard 112-2004, four different parameter estimation methods are presented [1]. The first, second and fourth methods require a locked rotor test which is considered too intrusive. Conversely, the third method involves only a no-load test. In this method, the test is done with the machine completely decoupled from its load and the voltage is reduced to achieve the machine's rated slip [1]. This method has the advantage that the locked rotor test is completely avoided; however, serious problems with regards to accuracy of the method have been observed in $[2,3]$.

A review of the major parameter estimation techniques is given in [4]. Generally, the methods for induction machine parameter identification can be classified into two, namely signal injection methods or system identification methods. Signal injection methods are usually performed at standstill with the motor excited with a dc or ac signal and the parameters are determined based on the resulting response. Several studies using signal injection method are reported [57]. However, the major drawback of this method is the problem of power dissipation and torque ripples [8]. System identification methods can be based on steady state measurements [9-14], or transient measurements [15-18]. Steady state methods use simplified motor models to solve the parameter estimation problem, but multiple test measurements at different loading conditions are required.

This paper presents the IEEE third impedance calculation method and proposes an improvement to 
the method for induction machine parameter identification using only no-load test measurements.

\section{IEEE STANDARD 112 THIRD IMPEDANCE CALCULATION METHOD}

The third impedance calculation method is one of the IEEE test procedures for calculating the equivalent circuit parameters of an induction machine [1]. This method is chosen in this work since it can be performed under no-load condition and does not require a locked rotor test. In the method, the motor is run uncoupled to a load and the voltage is reduced to achieve approximately the full load slip. Readings of voltage, current, power and temperature are taken at each voltage test point and an iterative procedure is followed to determine the equivalent circuit parameters. The test procedure as recommended by IEEE is presented as follows [1]:

\subsection{Stator Resistance Test}

With the machine at ambient temperature, the terminal-to-terminal resistance is measured. The average resistance is obtained using (1):

$$
R_{a v}=\frac{R_{a b}+R_{b c}+R_{c a}}{3}
$$

For a delta connection, the stator resistance is given by

$$
R_{1}=\frac{3}{2} R_{a v}
$$

The ambient temperature is also measured and recorded.

\subsection{No load Test}

The test is performed by running the machine with no load coupled to the shaft and at different voltage levels, starting from $125 \%$ of the rated voltage down to a point where further voltage reduction results in an increase in the current. In this paper, five different voltage points at $100 \%, 85 \%, 75 \%, 50 \%$ and $25 \%$ of the machine's rated voltage are considered for the noload test. From this test, the core loss as well as the curve of the total no-load reactance per phase versus phase voltage are determined.

\subsection{Equivalent Circuit Impedance Test}

The aim of this test is to find the equivalent circuit parameters of the induction machine. The parameters associated with equivalent circuit are the stator, rotor and magnetization resistances and reactances as depicted in Fig 1. From the no-load test data, the total reactance per phase is determined using (3)-(5).

$$
Q_{n l}=\sqrt{S_{n l}^{2}-P_{n l}^{2}}
$$

$$
\begin{gathered}
X_{n l}=\frac{Q_{n l}}{I_{n l}^{2}} \\
X_{n l}=X_{1}+X_{M}
\end{gathered}
$$

A curve of the total reactance against the phase voltage is obtained. The maximum point on the curve at point $\mathrm{D}$ as shown in Fig. 2 is taken as the total no-load reactance per phase.

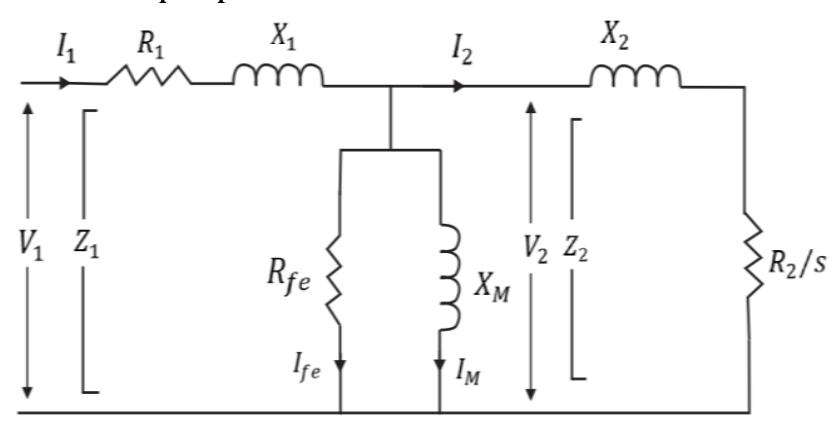

Fig. 1: Per phase equivalent circuit of an induction machine

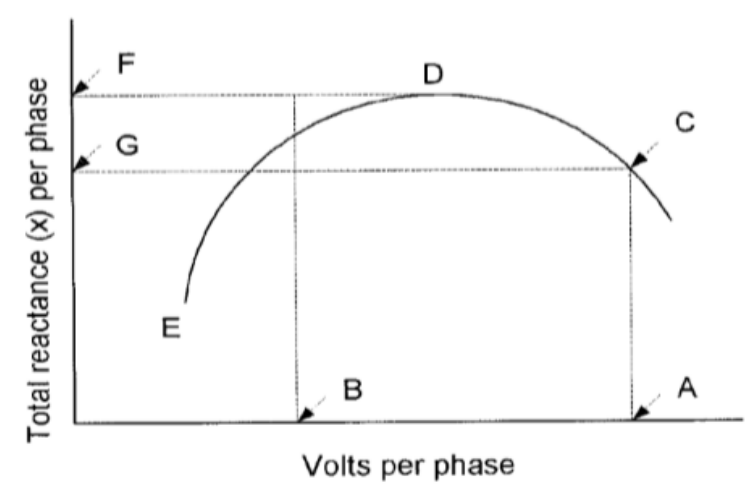

Fig. 2: Total reactance per phase from no load test [1]

From the reduced voltage test, the last operating point corresponding to the lowest voltage level $(i=5)$ is used to obtain the total apparent impedance per phase $Z_{i}$ and the power factor $p f_{i}$. The phase angle of the input current $\theta_{1, i}$, the total per phase apparent resistance $R_{i}$ and the total per phase apparent reactance $X_{i}$ are computed using (6) - (8) [1, 3]:

$$
\begin{gathered}
\theta_{1, i}=-\cos ^{-1} p f_{i} \\
R_{i}=Z_{i} \times \cos \left(-\theta_{1, i}\right) \\
X_{i}=Z_{i} \times \sin \left(-\theta_{1, i}\right)
\end{gathered}
$$

The value of $X_{i}$ computed using (8) corresponds to the total reactance per phase value at point $\mathrm{E}$ on Fig. 2. An initial estimate of the value of $X_{1}$ is calculated using (9) [1].

$$
X_{1}=X_{i}\left(\frac{X_{1} / X_{2}}{1+X_{1} / X_{2}}\right)
$$

The value of $X_{i}$ in (8) is used in (9) as the first estimate of the sum of the stator and rotor leakage reactances $\left(X_{1}+X_{2}\right)$. The ratio $X_{1} / X_{2}$ is obtained from the NEMA design details of the machine given in Table 1 [1]. Using the maximum value of the total no-load reactance 


\section{IDENTIFICATION OF INDUCTION MACHINE PARAMETERS USING ONLY NO-LOAD TEST MEASUREMENTS, M. Aminu, et al}

obtained from Point D on Fig. 2, the magnetizing reactance can be approximated as given in (10)

$$
X_{M}=\left(X_{1}+X_{M}\right)_{i}-X_{1}
$$

Table 1: Values of the ratio $X_{1} / X_{2}$

\begin{tabular}{lc}
\hline Design type & $X_{1} / X_{2}$ \\
\hline Wound rotor & 1.00 \\
Class A & 1.00 \\
Class B & 0.67 \\
Class C & 0.43 \\
Class D & 1.00 \\
\hline
\end{tabular}

Based on the lowest voltage test point from the no-load test (corresponding to $i=5$ ), equations (11) through (17) of the IEEE standard 112-2004 [1], [3] are used to calculate the rotor side voltage and current. These values are substituted into (18) to determine the rotor leakage reactance $X_{2}$.

$$
\begin{gathered}
V_{2, i}=\left(\left(V_{1, i}-I_{1, i}\left(R_{1 c} \cos \theta_{1, i}-X_{1} \sin \theta_{1, i}\right)^{2}\right.\right. \\
+\left(I_{1, i}\left(R_{1 c} \sin \theta_{1, i}+X_{1} \cos \theta_{1, i}\right)^{2}\right)^{\frac{1}{2}} \\
\theta_{2, i}=\tan ^{-1}\left(\frac{-I_{1, i}\left(R_{1 c} \sin \theta_{1, i}+X_{1} \cos \theta_{1, i}\right)}{V_{1, i}-I_{1, i}\left(R_{1 c} \cos \theta_{1, i}-X_{1} \sin \theta_{1, i}\right)}\right) \\
I_{M, i}=\frac{V_{2, i}}{X_{M}} \\
R_{f e, i}=\frac{V_{2, i}^{2}}{P_{h, i} / 3} \\
G_{f e, i}=\frac{1}{R_{f e, i}} \\
I_{f e, i}=\frac{V_{2, i}}{R_{f e, i}} \\
I_{2, i}=\left(\left(I_{1, i} \cos \theta_{1}-I_{M, i} \sin \theta_{2}-I_{f e, i} \cos \theta_{2}\right)^{2}\right. \\
+\left(I_{1, i} \sin \theta_{1}+I_{M, i} \cos \theta_{2}\right. \\
\left.\left.-I_{f e, i} \sin \theta_{2}\right)^{2}\right)^{\frac{1}{2}}
\end{gathered}
$$

Where $R_{1 c}=1.5 \times R_{d c}$ for delta connection and $R_{1 c}=0.5 \times R_{d c}$ for star connection. $P_{h, i}$ is the machine's core loss at the lowest voltage test point.

$$
\begin{gathered}
X_{2}=\frac{-V_{1, i} I_{1, i} \sin \theta_{1}-I_{1, i}^{2} X_{1}-I_{M, i}^{2} X_{M}}{I_{2, i}^{2}} \\
X_{i}=X_{1}+X_{2}
\end{gathered}
$$

Equations (9) through (19) are solved iteratively using the initial ratio of $X_{1} / X_{2}$ and the new value of $X_{i}$ until stable values of $X_{1}$ and $X_{2}$ are achieved within $0.1 \%$ [4]. The rotor resistance is obtained by (21).

$$
\begin{gathered}
Z_{2, i}=\frac{V_{2, i}}{I_{2, i}} \\
R_{2}=s \sqrt{Z_{2, i}^{2}-X_{2}^{2}}
\end{gathered}
$$

Where $\mathrm{s}$ is the slip.
A new value of $X_{M}$ is obtained using (22) by taking the value of the total no load reactance $\left(X_{1}+X_{M}\right)$ at point $\mathrm{C}$ on Fig. 2 (corresponds to point $i=1$ ) [1]. A new value is also obtained for $R_{f e}$

$$
\begin{gathered}
X_{M}=\left(X_{1}+X_{M}\right)_{1}-X_{1} \\
V_{2,1}=\left(\left(V_{1,1}-I_{1,1}\left(R_{1 c} \cos \theta_{1,1}-X_{1} \sin \theta_{1,1}\right)^{2}\right.\right. \\
+\left(I _ { 1 , 1 } \left(R_{1 c} \sin \theta_{1,1}\right.\right. \\
\left.\left.+X_{1} \cos \theta_{1,1}\right)^{2}\right)^{\frac{1}{2}} \\
R_{f e, 1}=\frac{V_{2,1}^{2}}{P_{h, 1} / 3}
\end{gathered}
$$

Finally, the equivalent circuit parameters $X_{1}, X_{2}$, $X_{M}$ and $R_{f e}$ are obtained using (9), (18), (21), (22) and (24) respectively. The rotor resistance $R_{2}$, obtained in (21) and the measured stator resistance $R_{1}$, are corrected to compensate for temperature changes using (25) [1].

$$
R_{c}=R \frac{T_{a}+K}{T+K}
$$

Where $R_{c}$ is the corrected resistance at a specified temperature, $R$ is the measured cold resistance at $T, T_{a}$ is the temperature to which the resistance is to be corrected and $K$ is the zero-resistance temperature constant $(\mathrm{K}=234.5$ for copper and $\mathrm{K}=224.1$ for aluminum).

Fig. 3 shows the flow chart of the parameter estimation algorithm.

\section{RESULTS AND DISCUSSIONS}

To verify the parameter estimation method, a $7.5 \mathrm{~kW}$ standard efficiency induction motor with nameplate data shown in Table 2 is tested. The laboratory experimental setup for testing the motor is shown in Fig. 4. Table 3 shows the results of the no-load test at the five voltage test points.

The standard no-load and block rotor test are performed three times and the average values obtained as shown in Table 4 . These results are used as a basis for comparison with the proposed method. Using the data in Table 3 for the for the $7.5 \mathrm{Kw}$ test motor core loss and the total per phase no-load reactance of the machine are determined as shown in Fig. 5 and Fig. 6 respectively.

The equivalent circuit parameters are determined using an iterative algorithm written in MATLAB 2014a. The algorithm uses the reactance values at the three points highlighted on the reactance versus voltage curve shown in Fig. 6. As shown in Fig. 7 and 8, the algorithm converges to stables values of $7.915 \Omega$ and $10.71 \Omega$ for the stator and rotor leakage reactances respectively. 
IDENTIFICATION OF INDUCTION MACHINE PARAMETERS USING ONLY NO-LOAD TEST MEASUREMENTS, M. Aminu, et al

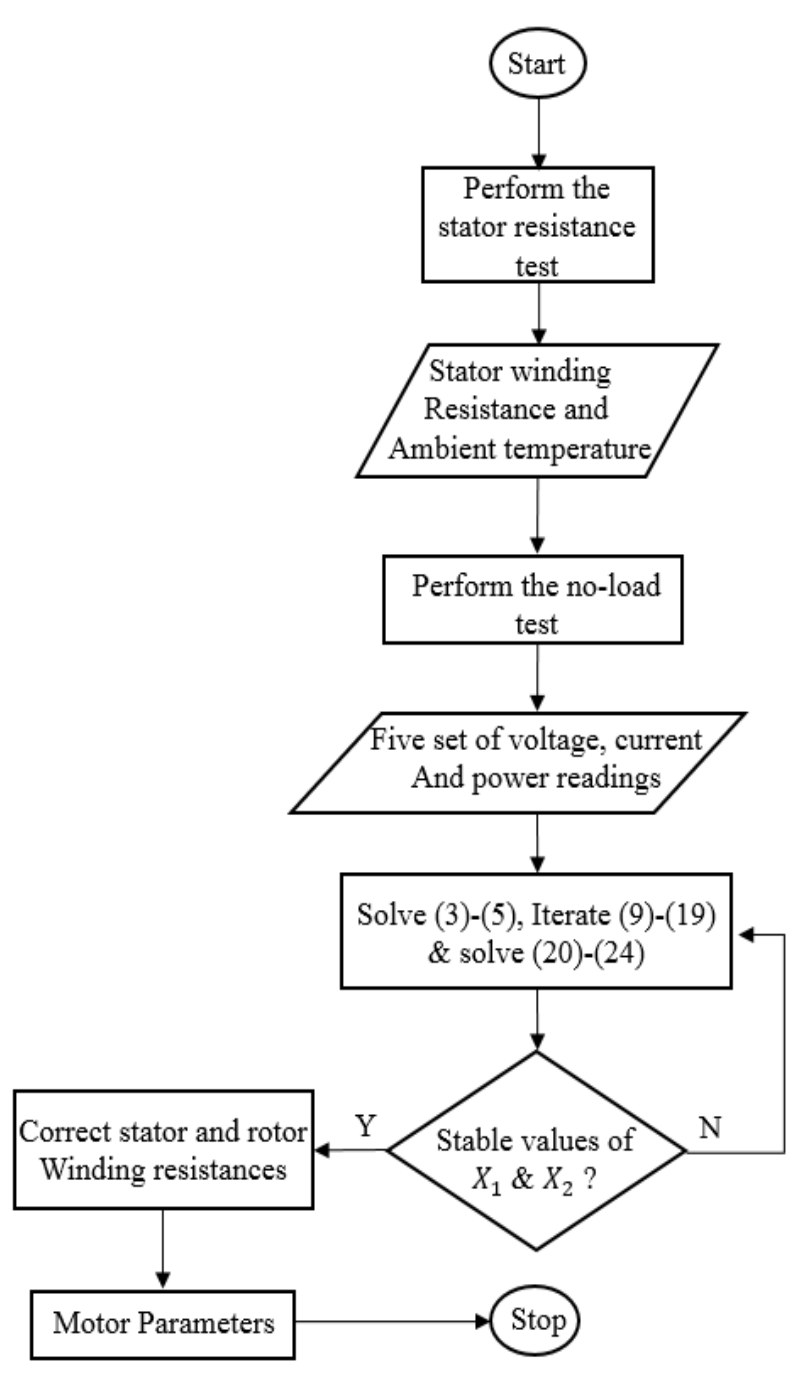

Fig. 3: Parameter estimation algorithm flow chart

The estimated parameters are summarized as shown in Table 4. The stator resistance is obtained through direct measurement across the terminals of the machine.

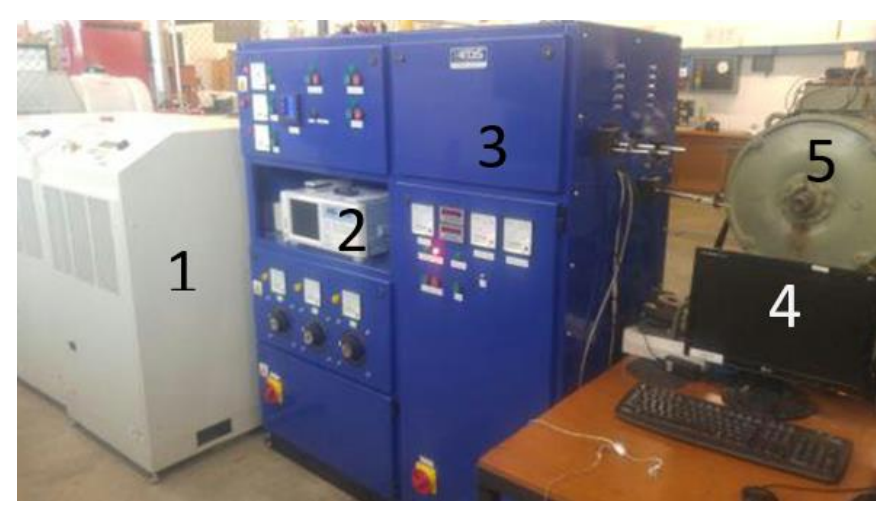

Fig. 4. Experimental Test Rig (1) Programmable power supply (2) Power analyzer (3) Control panel (4) Data acquisition pc (5) induction motor
Table 2: Nameplate data of Test Motor

\begin{tabular}{ll}
\hline Parameter & Value \\
\hline $\mathrm{V}_{\mathrm{LL}}$ & $7.5 \mathrm{~kW}$ \\
$\mathrm{I}_{\text {rated }}$ & $15.1 \mathrm{~A}$ \\
Frequency & $50 \mathrm{~Hz}$ \\
$\mathrm{n}_{\text {rated }}$ & $1450 \mathrm{rpm}$ \\
Poles & 4 \\
Class & $\mathrm{B}$ \\
Insulation & $\mathrm{F}$ \\
\hline
\end{tabular}

Table 3: No load Test results for the 7.5kW Motor

\begin{tabular}{cccccc}
\hline$i$ & $V_{1}(\%)$ & $V_{1}(V)$ & $I_{1}(A)$ & $P_{1}(W)$ & $T_{b}\left({ }^{\circ} \mathrm{C}\right)$ \\
\hline 1 & 100 & 381.32 & 5.79 & 413.47 & 48.66 \\
2 & 85 & 324.14 & 4.08 & 252.63 & 39.71 \\
3 & 75 & 286.01 & 3.45 & 193.21 & 37.05 \\
4 & 50 & 190.66 & 2.23 & 99.28 & 33.57 \\
5 & 25 & 95.29 & 1.16 & 47.45 & 31.07 \\
\hline
\end{tabular}

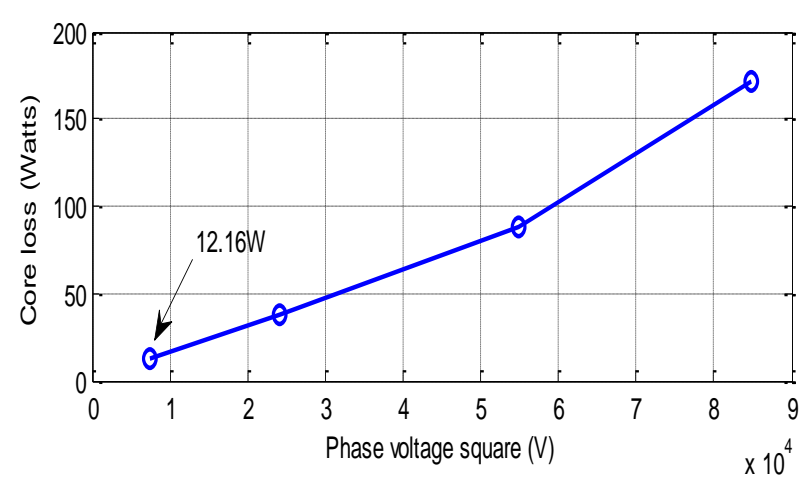

Fig. 5. Core loss vs phase voltage squared for the $7.5 \mathrm{~kW}$ motor

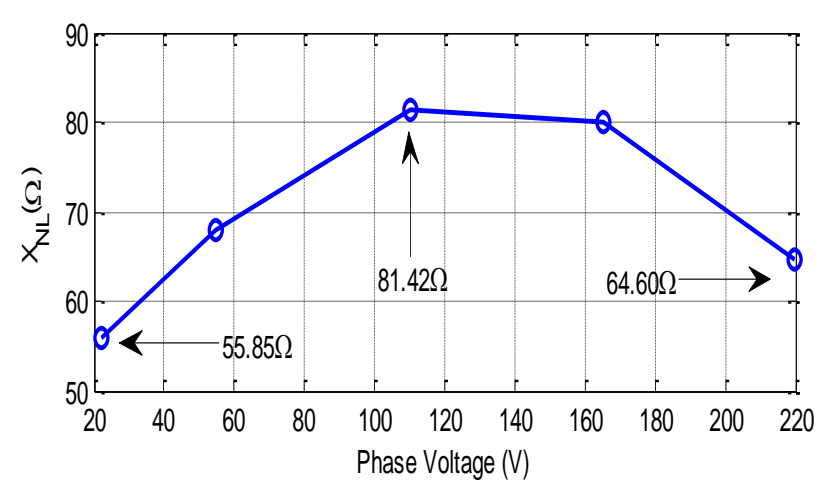

Fig. 6. Total no-load reactance vs phase voltage for the $7.5 \mathrm{~kW}$ motor 


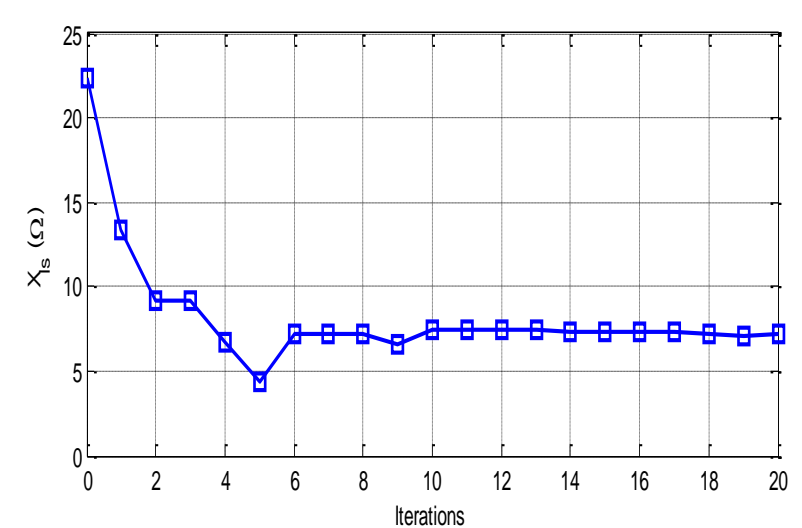

Fig. 7: Convergence profile of the stator leakage reactance

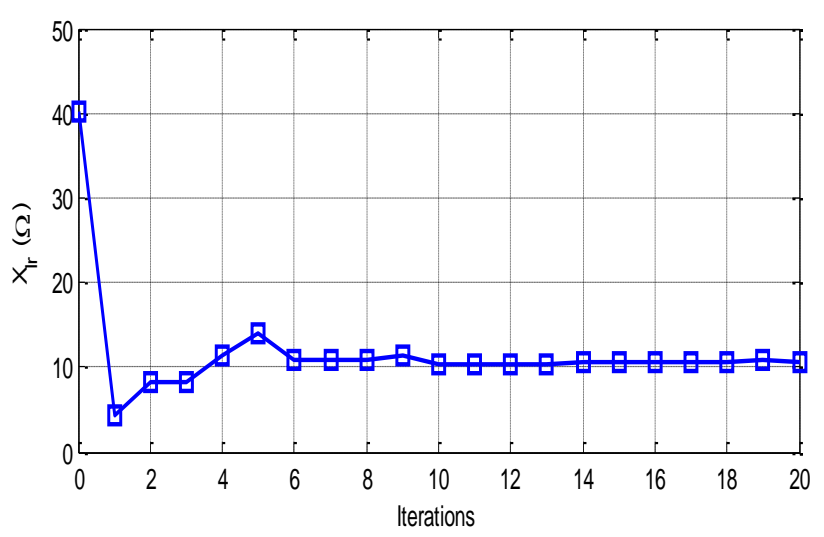

Fig. 8. Convergence profile of the rotor leakage reactance

Table 4: Parameters of the 7.5kW Induction Machine using the IEEE method

\begin{tabular}{ccccccc}
\hline \multicolumn{7}{c}{ No-load and block rotor test } \\
\hline Parameters & $R_{s}$ & $R_{r}$ & $X_{l s}$ & $X_{l r}$ & $X_{m}$ & $R_{f e}$ \\
\hline Mean value & 2.100 & 1.330 & 3.540 & 5.284 & 84.50 .000 & 1445.000 \\
\hline \multicolumn{7}{c}{ IEEE 112-Method 3 } \\
\hline Parameters & $R_{s}$ & $R_{r}$ & $X_{l s}$ & $X_{l r}$ & $X_{m}$ & $R_{f e}$ \\
\hline Mean value & 2.100 & 1.280 & 7.195 & 10.710 & 58.640 & 1250.000 \\
\hline
\end{tabular}

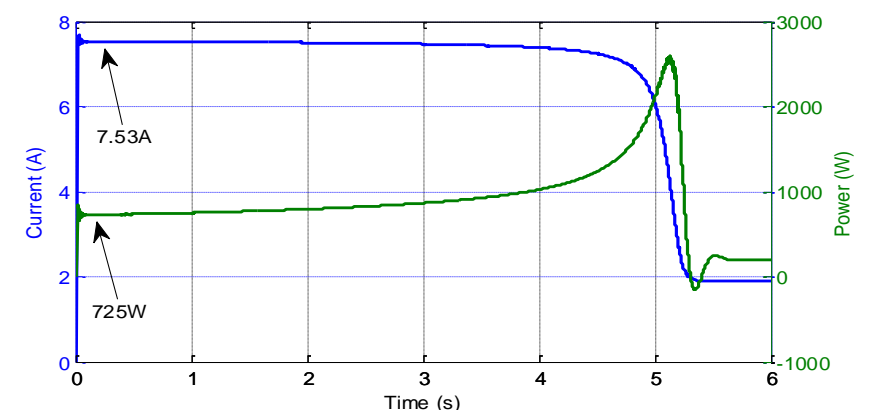

Fig. 10: Low voltage current and power curves

Based on the results shown in Table 4, it can be observed that the parameters obtained using the third impedance calculation method of the IEEE standard

112 are different from the ones obtained through the no-load and blocked rotor test. Higher values of stator and rotor winding leakage reactances are obtained in the IEEE method and this leads to a lower mutual reactance value.

To test the accuracy of the estimated parameters, the current versus voltage curve of the machine from experimental data is compared to the no-load and blocked rotor test and that of the IEEE third impedance method. The three curves are shown in Fig. 9. It can be observed that the error in the IEEE method is higher when compared to the conventional No-load and blocked rotor test. This means that parameters of the machine are not correctly estimated. This problem as observed in [2] is due to the assumption in the IEEE method that the stator and rotor leakage reactances found from the low voltage impedance test can also be used for the rated condition. However, due to the low level of current flowing in the machine in the low voltage region of the no-load test as can be observed in Table 3, the reluctance of the flux leakage path will be much smaller than its value under rated condition.

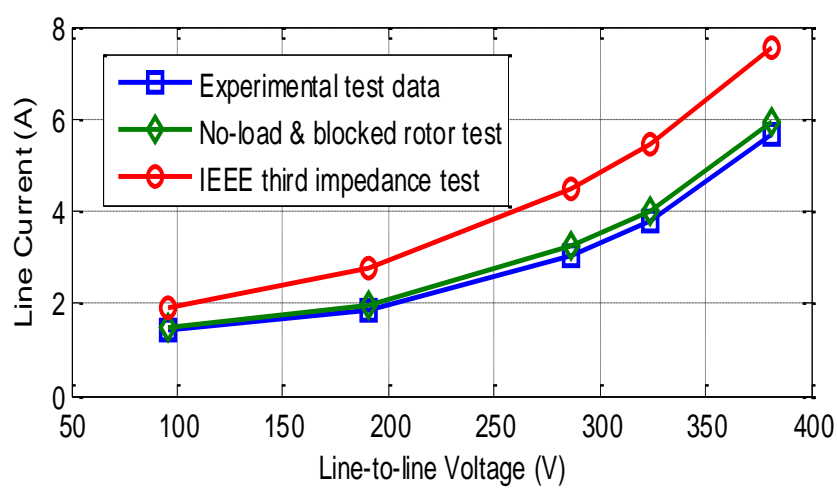

Fig. 9. Comparison of no-load current versus no-load voltage curves for the $7.5 \mathrm{~kW}$ motor

\subsection{Proposed Modification of the IEEE Method}

A simple method is proposed in this paper to find accurate leakage reactance values for the equivalent circuit based on the IEEE method. This method involves using the startup no-load current and power to determine the leakage reactance of the lowest voltage test point. As shown in Fig. 10, the values of the startup current and power after the initial ripples are much higher than their steady state values. Using these startup values for the lowest voltage point will give the right level of saturation in the machine and consequently correct the leakage reactance values. Under the startup condition, the machine operates in a condition similar to the locked rotor state, Thus, the total input reactance can be determined using (26) 


$$
X=\frac{V}{I}(\sqrt{1-P F})
$$

Where $X=X_{1}+X_{2}, V$ and $I$ are the phase voltage and current respectively and $P F$ is the power factor at the lowest voltage level test point.

The value of $X$ in (26) is used in (9) and the iteration procedure is repeated until stable parameter are obtained. The results obtained using this procedure are shown in Fig. 11 and 12. As can be seen from these figures, the stable values at the end of the iteration are much smaller and closer to the reference values than the ones obtained previously using the IEEE method.

Table 5 summarizes the results based on modified IEEE method and the percentage error when compared to the reference values.

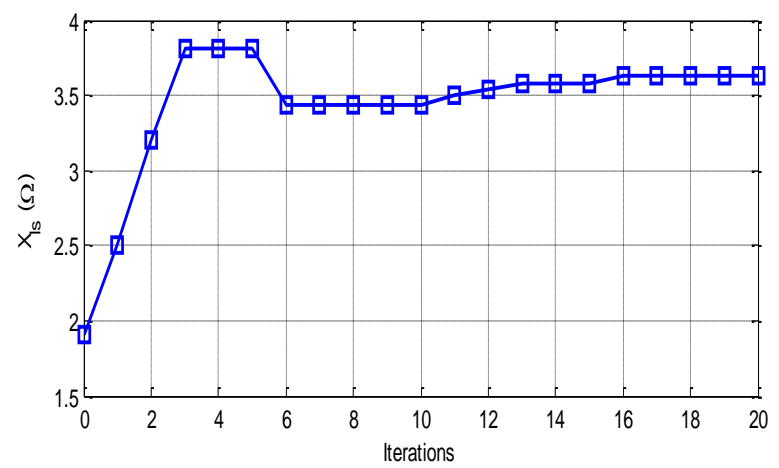

Fig. 11: Convergence profile of the stator leakage reactance

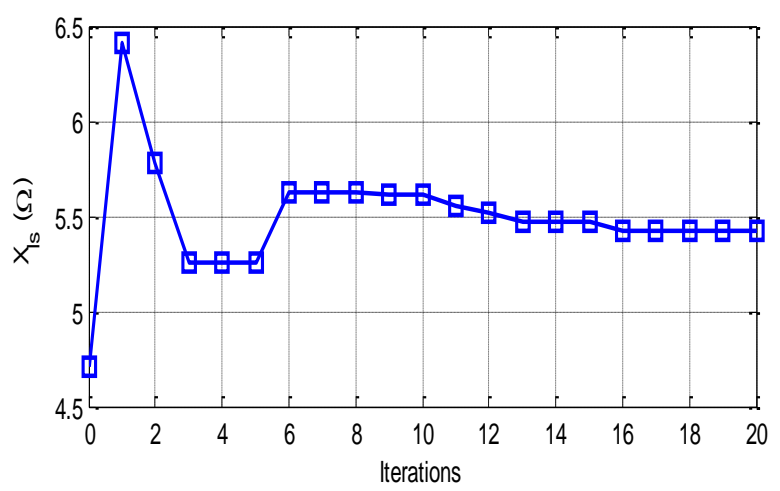

Fig. 12: Convergence profile of the stator leakage reactance

Table 5: Parameters of the 7.5kW Induction Machine using the modified IEEE method

\begin{tabular}{ccccccc}
\hline Parameters & $R_{s}^{*}$ & $R_{r}$ & $X_{l s}$ & $X_{l r}$ & $X_{m}$ & $R_{f e}$ \\
\hline Ref. & 2.100 & 1.330 & 3.540 & 5.284 & 84.50 .000 & 1445.000 \\
\hline $\begin{array}{c}\text { IEEE 112- } \\
\text { Method 3 }\end{array}$ & 2.100 & 1.280 & 7.195 & 10.710 & 58.640 & 1250.000 \\
\hline Error (\%) & 0.000 & 3.760 & -103.249 & -102.687 & 30.604 & -13.494 \\
\hline $\begin{array}{c}\text { Modified } \\
\text { IEEE 112- } \\
\text { Method 3 }\end{array}$ & 2.100 & 1.310 & 3.642 & 5.412 & 82.580 & 1432.000 \\
\hline Error (\%) & 0.000 & 1.504 & -2.881 & -2.422 & 2.272 & 0.899 \\
\hline
\end{tabular}

*Values obtained from direct measurements

\section{CONCLUSION}

This paper presented a simple yet accurate method of estimating the electrical parameters of an induction machine using only no-load test measurements. The method is based on IEEE standard 112 third impedance estimation with an improved leakage reactance calculation using the no-load startup power and current of the machine at the lowest voltage test point. The proposed method is simple and requires limited number of measurements. Additionally, the requirements in terms hardware are simple since the expensive dynamometer test as well as the locked rotor test are all avoided making it suitable for machine repair workshops. The accuracy of the proposed method is confirmed through experimental test results.

\section{REFERENCES}

[1] IEEE Standard Test Procedure for Polyphase Induction motors and Generators. IEEE Std 112, 2004.

[2] A. G. Siraki, P. Pillay, and P. Angers, "Full load efficiency estimation of refurbished induction machines from no-load testing," IEEE Trans. Energy Convers., vol. 28, no. 2, pp. 317-326, 2013.

[3] M. Al-badri, S. Member, P. Pillay, and P. Angers, "A Novel Algorithm for Estimating Refurbished Three-Phase Induction Motors Efficiency," IEEE Trans. Energy Convers., vol. 30, no. 2, pp. 615625, 2015.

[4] H. A. Toliyat, S. Member, E. Levi, S. Member, M. Raina, and S. Member, "A Review of RFO Induction Motor Parameter Estimation Techniques," IEEE Trans. on Energy Convers, vol. 18, no. 2, pp. 271-283, 2003.

[5] A. Bechouche, H. Sediki, D. O. Abdeslam, and S. Haddad, "A Novel Method for Identifying Parameters of Induction Motors at Standstill Using ADALINE," IEEE Trans. on Energy Convers, vol. 27, no. 1, pp. 105-116, 2012.

[6] M. Carraro and M. Zigliotto, "Automatic Parameter Identification of Inverter-Fed Induction Motors at Standstill," IEEE Trans. on Ind. Elect., vol. 61, no. 9, pp. 4605-4613, 2014.

[7] P. Castaldi and A. Tilli, "Parameter Estimation of Induction Motor at Standstill With Magnetic Flux Monitoring" IEEE Trans. on Cont. Sys. Tech. vol. 13, no. 3, pp. 386-400, 2005.

[8] B. Lu, T. G. Habetler, and R. G. Harley, “A Nonintrusive and In-Service Motor-Efficiency Estimation Method Using Air-Gap Torque With Considerations of Condition Monitoring," IEEE 


\section{IDENTIFICATION OF INDUCTION MACHINE PARAMETERS USING ONLY NO-LOAD TEST MEASUREMENTS, M. Aminu, et al}

Trans. on Ind. Applications, vol. 44, no. 6, pp. 1666-1674, 2008.

[9] A. Marcus and N. Lima, "Nonlinear parameter estimation of steady-state induction machine models," IEEE Trans. Ind. Electron., vol. 44, no. 3, pp. 390-397, 1997.

[10] B. Abdelhadi, A. Benoudjit, and N. Nait-Said, "Application of genetic algorithm with a novel adaptive scheme for the identification of induction machine parameters," IEEE Trans. Energy Convers., vol. 20, no. 2, pp. 284-291, 2005.

[11] M. Cirrincione, M. Pucci, G. Cirrincione, and G. A. Capolino, "Constrained minimization for parameter estimation of induction motors in saturated and unsaturated conditions," IEEE Trans. Ind. Electron., vol. 52, no. 5, pp. 13911402, 2005.

[12] M. H. Haque, "Determination of NEMA design induction motor parameters from manufacturer data," IEEE Trans. Energy Convers., vol. 23, no. 4, pp. 997-1004, 2008.

[13] E. Laroche and M. Boutayeb, "Identification of the induction motor in sinusoidal mode," IEEE Trans. Energy Convers., vol. 25, no. 1, pp. 11-19, 2010.
[14] D. M. Reed, H. F. Hofmann, S. Member, and J. Sun, "Offline Identification of Induction Machine Parameters With Core Loss Estimation Using the Stator Current Locus," IEEE Trans. on Energy Convers, vol. 31, no. 4, pp. 1549-1558, 2016.

[15] S. R. Shaw and S. B. Leeb, "Identification of induction motor parameters from transient stator current measurements," IEEE Trans. Ind. Electron., vol. 46, no. 1, pp. 139-149, 1999.

[16] M. Ranta and M. Hinkkanen, "Online identification of parameters defining the saturation characteristics of induction machines," IEEE Trans. Ind. Appl., vol. 49, no. 5, pp. 2136-2145, 2013.

[17] W. M. Lin, T. J. Su, and R. C. Wu, "Parameter identification of induction machine with a starting no-load low-voltage test," IEEE Trans. Ind. Electron., vol. 59, no. 1, pp. 352-360, 2012.

[18] J. Benzaquen, J. Rengifo, E. Albanez, and J. M. Aller, "Parameter Estimation for Deep-Bar Induction Machines Using Instantaneous Stator Measurements From a Direct Startup," IEEE Trans. Energy Convers., vol. 32, no. 2, pp. 516524, 2017. 